\title{
EĞLENCELİ ÜRÜN KARARLARI VE ÇOCUKLARIN SAĞLIKLI YIIYECEKLERE YÖNELIKK TUTUMLARI: KAVRAMSAL BİR ÇALIŞMA
}

\author{
JOYFUL PRODUCT DECISIONS AND CHILDREN'S ATTITUDES TOWARDS \\ HEALTHIER FOODS: A CONCEPTUAL STUDY
}

\section{DOI:10.17755/esosder.23827}

\section{Sertaç ÇiFCí ${ }^{1}$}

\section{$\ddot{O} \mathbf{z}$}

Günümüzde, aşırı şişmanlık ve sağlıksız beslenme, gün geçtikçe çocukların sağlıkları açısından tehlikeli bir hale gelmektedir. Çocuklar, bir tüketici olarak tecrübesizlikleri sonucunda, kendileri için zararlı olan ürünleri seçebilmektedir. Ailelerinin yanında iken bu tür durumlar karşısında korunabilen çocuklar, ailelerinin olmadığı ortamlarda, özellikle de okullarda, sağlıksız ürünler karşısında korumasızdır. Bu durumu engelleyebilmek amacıyla, yenilikçi ve yaratıı çözümlerin ortaya konulması oldukça önemlidir. Sosyal pazarlama bu noktada devreye girmektedir. Pazarlama aktiviteleri, mal ya da hizmet satma sürecinin dışında, sosyal fikir, davranış ve tutum değişikliği yaratmak için de kullanılmaktadır. Bu çalışmanın amacı, çocukların sağlıklı yiyeceklere yönelik tutumları üzerinde, pazarlama karması elemanı ürün kararlarından; marka ismi, ambalajlama, ürün besleyici bilgilerinin eğlenceli bir biçimde sunulmasının etkisinin kavramsal olarak tartışılmasıdır.

Anahtar Kelimeler: Eğlenceli ürün kararları, sağlıklı yiyeceklere yönelik tutum ve sosyal pazarlama faaliyetleri.

\begin{abstract}
Today, obesity and unhealthy diet is becoming dangerous for children's health day by day. Because of their inexperience as a consumer, they may choose harmful products. When they are with their families, they can be protected from such situations by their families but without their families, especially at school, they can be vulnerable to unhealthy food. In order to prevent this situation, it is very important to devise the innovative and creative solutions. Social marketing comes into play at this point. Marketing activities are not only used to sell the products but also sell the social idea, attitude and behavior. The aim of this study is to discuss the effects of joyful brand name, packaging, nutrition information on children's attitudes towards healthier food choice theoretically.
\end{abstract}

Keywords: Joyful product decisions, attitudes towards healthier foods, packaging, and social marketing activities.

\footnotetext{
${ }^{1}$ Yrd.Doç.Dr., Abant İzzet Baysal Üniversitesi, İİBF, İşletme Bölümü, sertacifci@yahoo.com
} 


\section{GİRİŞ}

Günümüzde aşırı şişmanlık ve sağlıksız beslenme çocuklar açısından oldukça tehlikelidir. Dünya Sağlık Örgütü'nün (WHO) verilerine göre, 2005 yılında 5 yaşının altında 20 milyon çocuk aşırı kiloludur. İngiltere'deki benzer bir veriye göre de, 2006 yılında yaşları 2 ile 15 arasında olan çocukların \%16'sı aşırı kiloludur. Bu veri 1995 yılı ile kıyaslandığında \%11'lik bir artışın olduğunu ortaya koymaktadır. Bu da, çocukların sağlık açısından gün geçtikçe tehlikeli bir duruma geldiğini göstermektedir (Neeleyve Petricone, 2006).

$\mathrm{Bu}$ durum hükümet yetkililerini, dünya sağlık örgütlerini ilgilendirdiği gibi aslında pazarlamayı da ilgilendirmektedir. Pazarlama ile ilgili yapılan en büyük eleştiri, belki de bireyleri gereksiz yere tüketime sevk etmesi yönünde yapılan eleştiridir. Etkili yöntemler kullanarak bireylerin dikkatinin çekilmesi, ikna edilmesi ve satın almaya yöneltilmesi temel sonuçları arasında gösterilmektedir.

Özellikle çocukların, çeşitli önlemlerle bu yöntemlerden korunması geniş çapta tartışılmaktadır. Çünkü çocukların bu tür uygulamalar karşısında korunmasız olduğu kabul edilmektedir. Bununla birlikte, bu etik sorun, pazarlamanın doğasından değil, kimi uygulayıcılarından kaynaklanmaktadır.

Pazarlamanın doğası, doğru tüketim ve tüketici korumayı da içermektedir. Pazarlama araçları etkin ve doğru bir şekilde kullanılabilir ise, tüketiciler açısından zararlı olmaktan öte, faydalı sonuçlar da doğurabilecektir. Sosyal pazarlama olarak ifade edilen kavram oldukça önemlidir. Sosyal pazarlama mesajları, mal ya da hizmetlerin tüketicilere satıldı̆̆ pazarlama prensipleriyle hareket etmektedir. Burada "satılan" ise fikirler, tutumlar veya davranışlardır (http://workingminds.org/marketing.html). Sosyal pazarlama, ticari pazarlamanın sosyal problemlere uygulanması olarak tanımlanabilir (http://ctb.ku.edu/en/sustain/social-marketing/overview/main).

Sosyal pazarlama kavramı, 1970'lerde Wiebe'nin önerileri ile ortaya çıkmış ve sosyal faydanın önde olduğu programları ifade etmektedir (Corner ve Randal, 2011). Neeleyve Petricone (2006)'in çalışması, çocukların çoğunlukla sıkıldıkları için gıda ürünlerinin ambalajında yer alan bilgileri okumadıklarını göstermektedir. Çocuklar bu tür bilgileri sıkıcı bulmakta ve ürün tercihlerinde bu tür bilgilere dikkat etmemektedir. Bu noktada ambalajlama çocuklara ulaşım için oldukça önemlidir (Young, 2004; Pires veAgante, 2011).

Çocuk odaklı gıda sektöründe, reklam kampanyaları çoğunlukla oyun veya eğlenceye yöneliktir (Villevd.,2010). Yapılan bu çalışmanın amacı, kavramsal olarak çocukların sağlıklı yiyeceklere yönelik tutumları üzerinde, pazarlama karması içerisinde yer alan ürün kararlarının etkisinin tartışılmasıdır. Bu amaçla, önce kavramsal çerçeveden, daha sonra da örneklerden bahsedilmiş, çalışmanın son kısmında ise tartışma ile uygulayıcılara yönelik önerilere yer verilmiştir.

\section{2. ÇOCUKLARDA SAĞLIKLI BESLENME VE SOSYAL PAZARLAMA}

Günümüzde sağlıklı beslenmeme ve hareketsizlik nedeniyle ortaya çıkan aşırı şişmanlık sorunu, toplumun her kesimindeki bireyleri olumsuz yönde etkilemektedir. Özellikle bu sorun, çocuklar ve gençler arasında, fast-food ve abur cubur (junkfood) tarzı yiyecekler nedeniyle giderek ciddi boyutlara ulaşmaktadır. Aşırı şişmanlık, daha sonra oluşabilecek ciddi kalp ve damar hastalıklarının yanı sıra, çocukların sosyalleşmesi üzerinde de oldukça etkilidir. 
Aşırı şişman çocukların, diğer yaşıtlarına kıyasla kendilerine daha az güven duydukları bilinmektedir (Dietz, 1998). Bu sorunun ne derecede tehlikeli boyutlara ulaştığını ortaya koyan ve Sağlık Bakanlığı Temel Sağlık Hizmetleri Genel Müdürlüğü tarafından 2011 yılında hazırlanan Türkiye'de Sağlıklı Beslenme ve Hareketli Hayat Programı raporunda, ülkemizde çocuklar arasında aşırı şişmanlığın boyutları, çeşitli araştırmaların sonuçları ile raporlanmıştır. Bu raporun içerisinde yer alan ve Büyükgebiz (2012) tarafından İstanbul'da yapılan bir çalışmada, 3-17 yaş grubu çocuklarda, aşırı şişmanlık görülme oranının kızlarda yüzde 14,7 , erkeklerde ise yüzde 18,7 olduğu, 10-12 yaş grubu erkeklerde ise bu oranın, yüzde 34,4'e kadar çıktığı belirlenmiştir. Aynı raporda yer alan ve Süzek vd., (2005) tarafından yapılan Kayseri ve Muğla illerini içeren bir diğer çalışmada da çocuklar arasında aşırı şişmanlığın görülme oranlarının yüzde 10’unun üzerinde olduğu tespit edilmiştir.

Sağlık Bakanlığı, Milli Eğitim Bakanlığı ve Hacettepe Üniversitesi Sağlık Bilimleri Fakültesi Beslenme ve Diyetetik Bölümünce yürütülen "Türkiye'de Okul Çağı Çocuklarında Büyümenin İzlenmesi Projesi" Araştırma Raporuna (2009) göre Türkiye'de yaşa göre çocukların durumu Tablo 1'de gösterilmiştir. Bu sonuçlar neredeyse her beş çocuktan birinin fazla kilolu ya da şişman olduğunu göstermektedir.

Tablo 1.Türkiye'de Okul Çağındaki Çocuklar ve Yaşa Göre Kilo Dağılımı

\begin{tabular}{cccc}
\hline Yaş & Fazla Kilolu & Şişman & Fazla Kilolu+Şişman \\
\hline 6Yaş & 12,4 & 5,5 & 17,9 \\
7Yaş & 15,3 & 5,8 & 21,1 \\
8Yaş & 14,4 & 6,1 & 20,5 \\
9Yaş & 14,1 & 7,7 & 21,8 \\
10Yaş & 14,5 & 6,9 & 21,4 \\
\hline
\end{tabular}

Kaynak:http://beslenme.gov.tr/index.php?lang=tr\&page $=40$

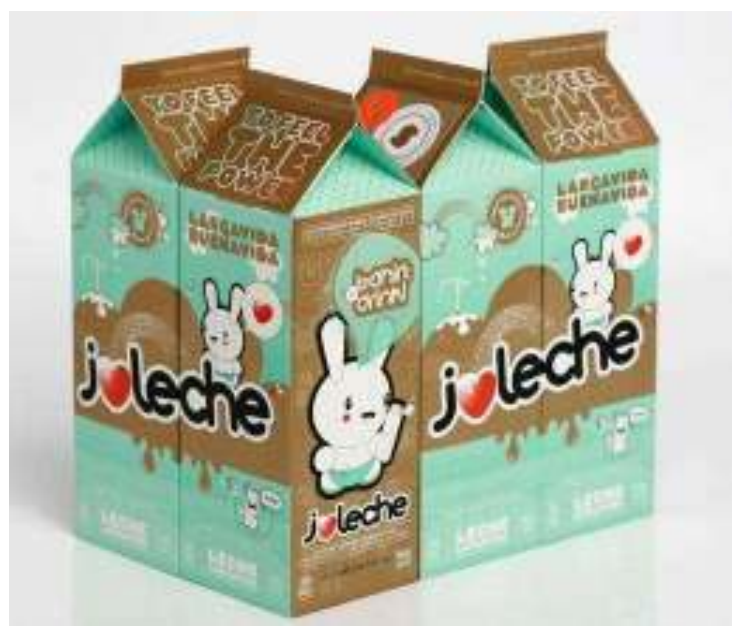

Şekil 1. Eğlenceli Ürün Ambalaj1

Kaynak:http://www.trendhunter.com/slideshow/milk-packaging 
Shepherd ve Dennison (1996) ve Elliott (2009)'ın çalışmanın başında bahsetmiş oldukları ve çocukların yararlı ürünlerine yönelmeleri için gerekli olan yaratıcı ve yenilikçi çözümler aslında bu çalışmada değinilen marka ismi, ambalajlama ve ürün bilgisini kapsamaktadır.

\section{EĞLENCELİ ÜRÜN KARARLARI VE COCUKLAR ÜZERİNDEKİ ETKİSI}

Marka isminin ve markalaşmanın, tüketicilerin ürün tercihleri üzerinde oldukça büyük bir etkisi vardır (Aaker, 1996). Bu kural sadece yetişkin tüketiciler için de geçerli değildir. Pazarlama içerisinde ürün kararları denildiğinde marka isim, sembol, slogan ile ambalaj ve paketleme akla gelmektedir. Tüm bunların çocukların ürün tercihleri üzerinde etkisi ortadadır.

McNeal (1992), çocukların erken yaşlardan itibaren, marka sadakati geliştirdiklerini ve belli başlı markalara karşı olumlu tutum sergilediklerini belirlemişlerdir. Robinson vd., (2007), marka bilinirliğinin, çocukların ürün tercihleri üzerindeki etkisini inceledikleri çalışmalarında, McDonald's markalı ambalaj ve markasız ambalajlı ürünleri ele aldıklarında, 3-5 yaş arasındaki çocukların, Mcdonald's markalı ambalajlı ürünün, diğerine kıyasla daha lezzetli bulduklarını saptamışlardır.

Levin ve Levin (2010)'de benzer biçimde, marka ismi ve isme yönelik yakınlığın, 7-8 yaş arasındaki çocukların ürün tercihleri üzerinde olumlu etkisinin olduğunu bulmuşlardır. McNeal (1992), Robinsonvd., (2007), Levin ve Levin (2010)'ın çalışmalarında da ifade ettikleri gibi marka, çocukların ürün tercihleri üzerinde oldukça etkilidir.

Çocuklar, erken yaşlardan itibaren markalara dikkat etmektedirler. Bu marka isimlerinin, özellikle abur cubur tarzı ürünlerde ilgi çekici olarak tasarlandığ 1 gözlemlenmektedir. Bu çerçevede eğlenceli marka kararları çocukların sağlıklı yiyecek tercihleri üzerindeki etkisi çalışmanın ilk önermesini oluşturmaktadır.

Önerme 1: Ĕ̆lenceli marka isim, sembol ve sloganı, çocukların sağllklı gıdalara yönelik tutumlarını olumlu yönde etkiler

Marka isminin yanı sıra, ürünün ambalajlamasının da önemi oldukça fazladır. Ghoshal vd., (2009), ilgi çekici ambalajlamanın, tüketicilerin ürün değerlendirmeleri üzerinde olumlu etkisinin olduğunu çalışmalarında bulmuşlardır. Şayet sunulan ürünün ambalajı ilgi çekicilik açısından üstün olur ise, ürüne karşı olan tutumda artacaktır.

Ambalajlamanın, çocukların sağlıklı ürün tercihleri üzerindeki etkisi çok az çalışmada ortaya konulmuştur. Bu çalışmaların en temeli, Pires ve Agente (2011)'nin yapmış oldukları ve ürün ambalajlamanın, çocukların daha sağlıklı ürünleri tercih etmeleri konusundaki etkisini ortaya koydukları çalışmadır. Aslında bu çalışma, bu proje fikrinin ortaya çıkmasında referans olunan çalışmadır. Yazarlar, abur cubur tarzı ürünlerin ambalajlarında yer alan özellikleri, sağlıklı ürünlere (elma) uyarlamışlardır.

Çocukların, ambalaj değerlendirmelerini, ürüne yönelik tutumda ambalajlamayı, algılanan sağlıklılığı ve satın alma niyetini ölçmüşlerdir. Çalışma sonuçlarında, ilgi çekici ambalajlamanın çocukların tutumları ve satın alma niyetleri üzerinde etkili olduğunu saptamışlardır.

Kısacası ambalajlama tüketicilerin ürün tercihlerinde oldukça etkilidir (Ghoshal vd., 2009) ve çocuklarda özelikle ilgi çekici ambalajlı ürünleri tercih etmektedir (Pires ve Agente, 2011). Bu çalışmanın ikinci önermesi de benzer biçimde eğlenceli ambalajlamanın, çocukların sağlıklı yiyecek tercihleri üzerindeki etkisinin olumlu olmasıdır. 
Önerme 2: Ĕ̆lenceli ambalajlama kararları çocukların să̆lıklı gıdalara yönelik tutumlarını olumlu yönde etkiler
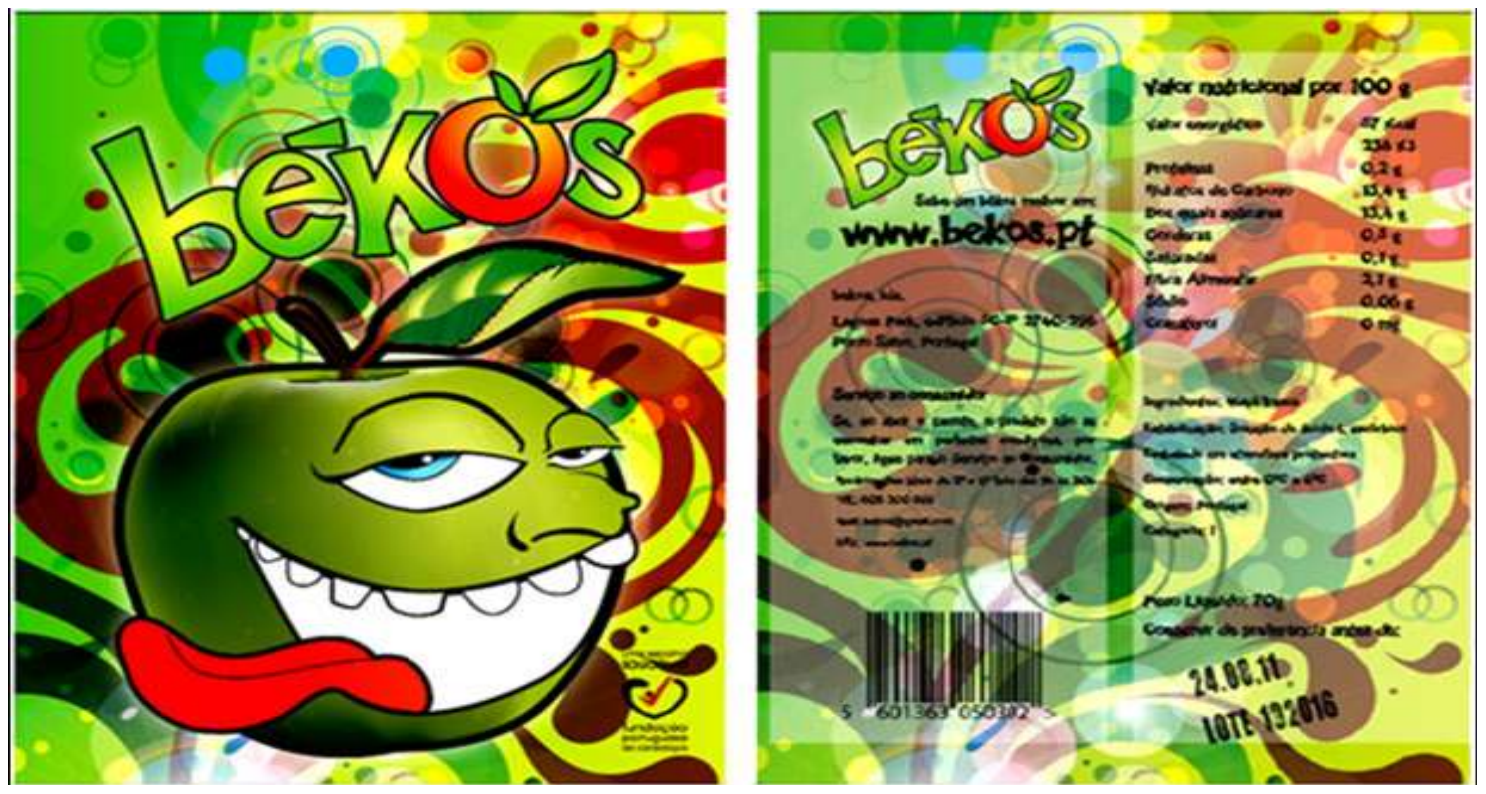

Şekil 2. Eğlenceli Sağlıklı Ürün Ambalajı

Kaynak:Pires, C.,Agante, L. (2011) "Encouraging to Eat More Healthily: The Influence Packaiging", Journal of Consumer Behaviour, 10: 161-168.

Eğlenceli ürün kararları sadece ürüne olan ilginin artırılmasına değil aynı zamanda da ürün besleyici bilgilerinin çocuklar tarafından fark edilmesine de kolaylık sağlayabilir. Bireyleri, daha sağlıklı beslenmeleri konusunda cesaretlendirmede, ürünlerin besleyici özelliklerinin ve kalorilerinin açık bir şekilde ve anlaşılır bir biçimde yazılmasının önemi oldukça fazladır.

Yetişkin bireyler, çoğu zaman uygulamaya geçirmemelerine karşın, ürünlerin sağliklı olup-olmadıkları konusunda genellikle bilinçlidirler. Buna karşın, çocuklar, ürünlerin sağlıklı olup-olmaması konusundaki en basit bilgileri bile anlamakta sorun yaşayabilirler (Neeley ve Petricone, 2006). Çocuklar, genellikle ürünün besleyici değeri ile ilgili bilgileri ailelerinden öğrenmektedir (Goldbergvd., 1978) ve bu tür bilgileri genellikle sıkıcı bulmaktadır. Bu durum, çocukların ürünlerin ambalajlarının üzerinde yazan bu bilgileri okumamalarını ve dolayısıyla ürün yararları hakkında bilgi sahibi olamamalarına neden olmaktadır.

Neeley ve Petricone (2006), 7-12 yaş grubundaki çocuklarla yaptıkları çalışmada, ürün ambalajlarında yer alan ürün besleyici bilgilerini ne kadar anladıkları konusunda yaptıkları çalışmalarının sonucunda, çocukların bu bilgilere dikkate almaları açısından görsel gösterimlerin önemli olduğunu ifade etmişlerdir. Hart vd., (2002)'de İngiltere'de ilkokul çağındaki çocukların ürün besleyici bilgilerini ne derecede anladıkları ve onların anlayabilmesi için en etkili yolların ne olacağına ilişkin bir çalışma gerçekleştirmişlerdir. $\mathrm{Bu}$ çalışma sonuçlarında çocukların, kendilerine yakın hissettikleri ürün gruplarında yer alan ürünlerin besleyici bilgilerine daha dikkat ettikleri sonucuna ulaşmışlardır. Etiket olarak ifade edilen ürün bilgisi, tüketiciler açısından oldukça önemlidir.

Yetişkin bireyler, bu bilgileri rahatlıkla okuyabilmektedir. Çocukların ise hemen hemen hiç dikkatini çekmemektedir. Neeley ve Petricone (2006) ve Hart vd., (2002)'nin belirtikleri gibi ürün bilgisinin ilgi çekici sunumu oldukça önemlidir. $\mathrm{Bu}$ da, ürün besleyici 
bilgilerinin görsel ve yazılı bir biçimde eğlenceli olarak verilmesinin onların farkındalıklarını artırabileceğini göstermektedir.

Önerme 3: Eğlenceli ürün besleyici bilgileri, çocukların ürün besleyici bilgilerine yönelik farkındalıkları üzerinde olumlu etki oluşturmaktadır.

\section{TARTIŞMA VE ÖNERILER}

Pek çok kişi, pazarlamayı, aşırı tüketimi körükleyen, satın alma davranışına gereksiz yere sevk eden özelliklere sahip olarak bilinmektedir. Oysa pazarlamanın amacı, aşırı tüketime yönlendirmek değildir. Pazarlama, tüketicilerin ihtiyaçlarını gidermede, doğru yerde, doğru zamanda, doğru miktarda ve doğru tüketimi özendirmektedir. Örneğin, pazarlama kararlarından birisi olan markayı ele alalım. Tüketiciyi koruma, bir sorunla karşılaştığında muhatabı bilebilme, yanlış tercih yapmama gibi pek çok avantaj, markanın tüketicilere sağladığı faydalardan sadece bazılarıdır.

Pazarlamanın gerçek anlamı ve amacı, tüketicileri doğru ürünlere yönlendirmektir. Çocuklar açısından, özellikle de yiyecek-içecek kararlarında oldukça önem taşımaktadır. Bu çalışmanın özgün değeri işte bu şekilde yapılacak ürün kararlarının, çocukların sağlıklı yiyeceklere yönlendirilmesi üzerindeki etkisinin kavramsal olarak tartışılmasıdır.

$\mathrm{Bu}$ kapsamda günümüzün en önemli sorunlarından olan aşırı şişmanlık ve sağlıksız beslenme, toplumun her kesimini, özellikle de çocukları olumsuz etkilemektedir. Bu çalışma sonucunda, araştırma hipotezlerinin desteklenmesi halinde, çocukları daha sağlıklı gıda ürünlerine yönelmelerini sağlayabilecek olan, eğlenceli marka ismi, ambalajlama, sunum ve ürün besleyici bilgilerinin etkisi ortaya konulmuş olacaktır. $\mathrm{Bu}$ da, çocukların bu tür zararlı gıdalardan uzak tutmak konusunda ilgili bakanlık, kurum ve kuruluşlara çeşitli öneriler sunulabilecektir.

İşletmeler, sosyal sorumluluk anlayışları gereği, çocukların korunması konusuna özel önlem vermek durumundadır. Bunun yanı sıra, pazarlama stratejilerinin çocukların sağlıklı gıdalara yönelmeleri konusunda yeniden düşünülmesi ve planlanması gereklidir.

\section{KAYNAKÇA}

Aaker, D. A. (1991). Managing Brand Equity. Free Press, New York.

Audrey, C., McCool E. R. D., Myung, E. ve Chien, T. C. (2005). "Modification of the Form in Which Fresh Fruit is Served as a Possible Means of Increasing the Consumption of Fruit Offered to Elementary and Middle School Students", Journal of Foodservice Business Research, 8/2, 73-85.

Büyükgebiz, B. "Büyüme ve İştah Bozuklukları ve Obezite". http://www.istahsizcocuk.com/buyume_dosyalar/obezite.ht, Erişimtarihi: 06/02/2012.

Corner, A. ve Randall, A. (2011). "Selling Climate Change? The Limitations Of Social Marketing As A Strategy For Climate Change Public Engagement",Global Environmental Change, 21/3, 1005-1014.

Dietz, W. H. (1998).“Health Consequences of Obesity in Youth: Childhood Predictors of Adult Disease", Pediatrics, 101/2, 518-525.

Dixona, H. G.,Scullya, M. L., Wakefielda, M. A., Whitea, V. M. ve Crawford, D. A. (2007)."The Effects of Television Advertisements for Junk Food Versus Nutritious Food on Children's Food Attitudes and Preferences", Social Science \& Medicine, 65, 1311-1323. 
Elliott, C. (2008). "Marketing Fun Foods: A Profile and Analysis of Supermarket Food Messages Targeted at Children”, Canadian Public Policy, 34/2, 259-273.

Ghoshal, T., Boatwright, P, ve Cagan, J. (2009)."Unwrapping The Good News: Packaging Pays, and "How" The Role of Packaging in Influencing Product Valuation",Advances in Consumer Research, 8, 254-256.

Goldberg, M. E., Gorn, G. J. ve Gibson, W. (1978). "TV Messages for Snack and Breakfast Foods: Do They Influence Children's Preferences?”,Journal of Consumer Research, $5 / 2,73-81$.

Greig, A. D., Taylor, J. ve MacKay, T. (2007).Doing Research with Children, second edition, Sage Publications Inc: London.

Hart, K. H., Bishop J. A. ve Truby, H. (2002).“An Investigation into School Children's Knowledge and Awareness of Food and Nutrition", Journal of Human Nutrition and Dietetics, 15/2, 129-140.

Hunter, B. T. (2002).“Marketing Foods to Kids: Using Fun to Sell”, Consumers' Research Magazine, March.

Krassas, G. E., Tsametisi C., Baleki, V., Constantinidis, T.,Ünlühizarcı, K., Kurtoğlu, S. ve Keleptimur, F. (2004). "Balkan Group for the Study of Obesity. Prevalence of Overweight and Obesity Among Children and Adolescents in Thessaloniki-Greece and Kayseri-Turkey", Pediatr Endocrino Rev, 1/3, 460-464.

Levin A. M. ve Levin, I. P. (2010).” Packaging of Healthy and Unhealthy Food Products for Children and Parents: The Relative Influence of Licensed Characters and Brand Names", Journal of Consumer Behaviour, 9/5, 393-402.

Mangleburg, T. F. ve Tech, V. (1990) “Children's Influence In Purchase Decisions: A Review and Critique", Advances in Consumer Research, 17, 813-825.

Mcneal, J. U. (1992).Kids as Customers: A Handbook of Marketing to Children, Lexington Books, New York.

Neeley, S. M. ve Petricone, B. (2006).“Children's (Mis)understanding of Nutritional Information on Product Packages: Seeking Ways to Help Kids Make Healthier Food Choices", Advances in Consumer Research, 33, 556.

Pires, C. ve Agenta, L. (2011). "Encouring Children to Eat More Healthily: The Influence of Packaiging”, Journal of Consumer Behaviour, 10, 161-168.

Shepherd, R. ve Dennison, C. M. (1996).“Influences on Adolescent Food Choice”,Institute of Food Research, 55, 345-357.

Süzek, H., Arı, Z. ve Uyanık, B. S. (2005). "Muğla'da Yaşayan 6-15 Yaş Okul Çocuklarında Kilo Fazlalığı ve Obezite Prevalansı”, Türk Biyokimya Dergisi, 30/4, 290-295.

Türkiye Sağlıklı Beslenme ve Hareketli Hayat Programı, Sağlık Bakanlığı, Temel Sağlık Hizmetleri Genel Müdürlüğ̈̈, Ankara, 2011.

Valkenburg, P. M. ve Cantor J. (2001). "The Development of A Child into a Consumer", Applied Developmental Psychology, 22, 61-72.

Ville, V. D. L., Brougere, G. ve Boireau, N. (2010) "How Can Food Become Fun? Exploring and Testing Possibilities", Young Consumers: Insight and Ideas for Responsible Marketers, 11/2, 117-130. 
Wiebe, G.D.(1952). Merchandising Commodities and Citizenship On Television”,Public Opinion Quarterly, 15, 679-691.

Young S. (2004). "Winning at Retail: Research Insights to Improve. The Packaging of Children's Products", Young Consumers: Insight and Ideas for Responsible Marketers, 5/1, 17-22. 